\title{
VARIAÇŌES ESTACIONAIS NO PELAME DE VACAS DA RAÇA JERSEY E SUA CORRELAÇÃO COM A PRODUÇÃO LEITEIRA
}

BARNABE, R. C. - Variaçōes estacionais no pelame de vacas da raça Jersey e sua correlação com a produção leiteira. Rev. Fac. Med. vet. Zootec. Univ. S. Paulo, 12:95-106, 1975.

Resumo: A espessura do pelame, medida em 4 regiōes do corpo (paleta, dorso, garupa e costado) de 45 vacas da raça Jersey e tomada no inverno $e$ no verão, foi relacionada com a produção leiteira desses mesmos animais.

Os dados obtidos foram submetidos ao teste de " $F$ ", revelando apenas não ser significativa a interação animais $x$ região do corpo, indicando que os animais comportam-se igualmente quanto à espessura do pelame em relaçāo às regiōes do corpo, independentemente da estação do ano.

De um modo geral, os animais apresentaram espessura do pelame diversa uns dos outros. Verificou-se ainda que as espessuras sāo distintas em relação às regiōes do corpo em que foram medidas, bem como que diferem segundo as estaçōes.

As correlaçōes entre espessura de pelame e produçāo leiteira indicaram a tendência de aninais de pelame menos espesso apresentarem indices de lactaçōes mais elevados, uma vez que todos os coeficientes foram negativos.

Os coeficientes relativos às regiōes da paleta e do costado, no verão, atingiram niveis de significância mais elevados. $d u c ̧ a \tilde{a} o^{*}$.

Unitermos: Variaçöes estacionais*; Pelame, espessura*; Leite, pro-

\section{N T R O D U Ç $\tilde{A} O$}

Nem sempre as tentativas de adaptação de gado leiteiro, oriundo das zonas temperadas, às regiões tropicais e subtropicais, resultam de todo satisfatórias.

o problema da adaptação requer dos animais, características especiais que possibilitem-lhes reagir, com maior ou menor efeito, às condiçôes impostas pelo ambiente.
A capacidade do bovino para resistir a essas condiçōes mede-se, diretamente, pelas reações imediatas através das variações de temperatura corporal e de freqüência dos movimentos respiratórios e, remotamente, em termos de produtividade, isto é, desenvolvimento ponderal, reprodução e produção de leite, quando se trate de gado leiteiro.

* Professor Assistente Doutor.

Departamento de Cirurgia e Obstetricia da Faculdade de Medicina Veterinária e Zootecnia da U.S.P. 
BARNABE, R. C. - Variações estacionais no pelame de vacas da raça Jersey e sua correlação com a produção leiteira. Rev. Fac. Med. vct. Zootec. Univ. S. Paulo, 12:95-106, 1975.

Grande parte do calor de um bovino elimina-se através da pele, a qual encontra-se quase totalmente revestida de pelos. Assim, estes representam obstáculo a ser vencido na dissipação do calor corporal. o pelame de revestimento é bastante diverso de um para outro tipo de bovino, de uma para outra raça e mesmo, de um para outro indivíduo.

Os pelos dos bovinos parecem renovar-se contínua e ritmicamente, segundo as estações do ano. Não deixa de ser significativo o fato de os bovinos apresentarem pelos mais longos no inverno, mudando este aspecto pela queda e substituição por outros novos que, no verão, se apresentam mais curtos, formando camadas nitidamente mais delgadas. E certo que essas mudanças podem também ser influenciadas por distúrbios nutricionais - carências vitamínicas ou minerais - , por perturbações glandulares ou por enfermidades.

O objetivo do presente trabalho foi investigar as possíveis relações entre espessura do pelame de revestimento e produção leiteira de vacas da raça Jersey. Procuramos, por outro lado, verificar a variação estacional entre inverno e verão, que ocorreria na espessura de quatro regiões do pelame (paleta, dorso, garupa e costado) de animais dessa raça, com a finalidade de averiguar se aqueles de melhores produções exibiriam alguma característica de pelame mais de perto relacionada com essas duas estações.

\section{I T E R A T U R A}

Trabalhos pioneiros 26 revelaram que o bovino de origem indiana (Bos indicus) têm maior tolerância ao calor ambiente dos climas tropicais e subtropicais, o que nāo ocorre em geral com animais de origem européia (Bos taurus).

Nos componentes do organismo, na forma e na estrutura de determinados tecidos, principalmente considerando a fisiologia de certas funçōes e do próprio metabolismo, encontram-se fortes indícios de suas relacões com a capacidade individual de tolerância ao calor.

Dentre tais características tem sido ressaltada a importância da pele e dos pelos dos bovinos em seus vários componentes estruturais e em seu comportamento fisiológico9.
O pelame, dependendo de suas caracteristicas que lhe conferem maior ou menor capacidade isolante, se constitui em barreira a ser vencida pelo calor que será eliminado ou absorvido pelo organismo, dependendo do meio ambiente. A carga de radiação solar absorvida por um animal pode depender das características de seus pelos que, por mecanismos de reflexão e convexão, têm a faculdade de dissipar parte da radiação recebida, antes desta haver atingido a pele do animal. Por outro lado, a perda de calor corporal através da superfície cutânea se processa com intensidades diferentes, de acordo com a espessura do pelame e as características dos próprios pelos ${ }^{14}$.

Os bovinos sofrem mudas dos pelos, orientada por modificaçōes do clima, de acordo com as estações do ano. Há indicações também de que a renovação dos pelos seja influenciada, em condições normais, pelo número de horas de luz e pela temperatura ambiente, fatores estes que aumentam do inverno para o verão ${ }^{38}$.

Os folículos pilosos mantêm processo de crescimento em todas as estações, mas o maior número deles atinge fase mais ativa em determinadas épocas do ano13. Verificou-se também que o processo de substituição é contínuo, sendo entretanto mais intenso no verão17.

Nos trópicos e nas regiões subtropicais não há invernos rigorosos e prolongados, e temperaturas ambientes próximas da temperatura corporal são as condições que predominam. Observa-se, nos bovinos dos trópicos, os zebuinos, que seus pelos são mais curtos que os dos bovinos europeus em qualquer época do ano, embora também eles apresentem mudanças dos pelos do inverso para o verão. Mas é evidente que, mesmo mais curtos no verão que no inverno, os pelos dos animais europeus, nos ambientes tropicais, ainda podem constituir séria barreira para a dissipação do calor corporal34. Esses trabalhos revelaram que, no Estado de São Paulo, em zona situada entre os paralelos 21 e 24 de latitude sul, os representantes da raça Jersey apresentavam pelame nitidamente menos espesso que o de duas outras raças de origem européia, Holandesa preta e branca e Schwitz. O pelame do gado Jersey, considerado em sua espessura, foi o que mais se aproximou daqueles apresentados por exemplares indianos das raças Gir, Nelore, Guzerá e Indubrasil, no verão e no inverno. Ficou claramente evidenciada a va- 
BARNABE, R. C. - Variaçōes estacionais no pelame de vacas da raça Jersey e sua correlação com a produçāo leiteira. Rev. Fac. Med. vet. Zootec. Univ. S. Paulo, 12:95-106, 1975.

riabilidade entre indivíduos de uma mesma raça, havendo alguns dentre os da raça Jersey, que não se diferenciavam de zebus nesse particular.

O comprimento do pelo de animais da raça Jersey comparado com o da raça indiana Sahiwal revelou-se mais longo 23. Verificou-se ainda que dentro de uma mesma raça européia e também de raça nativa dos trópicos, a Afrikander, era tarefa fácil separar bezerros de maior ou menor espessura de pelame, logo por ocasião do nascimento5. A influência da velocidade de crescimento dos pelos na adaptação dos animais aos climas quentes também foi investigada24. Os animais portadores de sague europeu apresentaram a maior velocidade no crescimento dos pelos, conquanto diferenças menos sensiveis fossem verificadas, nesse particular, entre indivíduos.

Uma prova para indicar precocemente os animais que podr-iam melhor se adaptar às condiçōes dos trópicos foi preconizada na Africa do Sul3, consistindo em se retirar uma porção de pelos de um bezerro, esfregando-a sobre a palma da māo com os dedos, depois de levemente umedecida. Os pelos que por esse método se aglutinarem como feltro seriam os que mais prejudicariam os animais nos trópicos. Assim, tornou-se possível 4 desenvolver uma linhagem de bovinos da raça Hereford de pelos curtos e lisos, muito mais resistente que o Hereford comum. A possibilidade de escolher animais de pelos curtos, mais apropriada para ambientes de temperatura elevada, foi assim demonstrada. Aliás, a influência hereditária das características do pelame de vacas da raça Holandesa sobre os seus descendentes também foi revelada ${ }^{18}$.

Outras observaçōes foram feitas 6,21 ainda na Africa do Sul, assinalando as acentuadas reações de desconforto apresentadas por bovinos Afrikander, providos de pelos lanosos, ásperos, bem como por animais da raça Hereford, mesmo de pelos lisos.

A presteza com que os bovinos efetuam a muda dos pelos do inverno também pode influir na tolerância desses animais ao calor e em seu p-ípris desenvolviminto nos trópicos10. Verificou-se que os animais que no verāo já haviam trocado todo o pelame de inverno, eram justamente os mais desenvolvidos.
Um método subjetivo de avaliação que levava em consideração desde os pelos extremamente curtos e lisos até os mais longos e crespos foi idealizado32. Atribuindo a cada tipo de pelame um valor, estabeleceram-se estreitas relaçōes entre características dos pelos e desenvolvimento ponderal dos animais. Experimentos posteriores 33 esclareceram que dentre as características do pelame, a espessura observada no fim da primavera se revestia de maior importância para a previsão dos resultados. Argumentou-se, também, que a prova para a formação de feltro13, embora oferecesse útil informação, não seria de molde a sobrepujar o método de classificaçāo proposto, pois este abrangia toda a superfície corporal, ao passo que aquele se limitava apenas a uma amostra de pelos cortados.

Em trabalho realizado com animais $d a$ raça Shorthorn 38 , foi demonstrado que o ritmo da muda dos pelos podia ser modificado, independentemente das temperaturas estacionais, mediante alterações do numero de horas de luz a que os animais estivessem submetidos. Pelo emprego de luz artificial no inverno e reduzindo o período de luz no verão, mediante colocaçāo dos animais em compartimentos escuros, conseguiu-se alterar as características do pelame, assumindo, no verão, pelame de inverno e, no inverno, pelame de verão.

Posteriormente, simulando o fotoperiodismo equatorial, com número de horas de luz constante39, verificou-se que nessas condições, os bovinos de origem européia apresentavam certas dificuldades na substituição de seus pelos abundantes e espessos, o que acarretava sérios obstáculos à sua adaptação. Não haveria, por conseguinte, estação de escolha para se proceder à transferência de animais das zonas temperadas para a zona equatorial, embora essas transferências parecessem mais favoráveis na primavera e no outono de seus paises de origem.

Entretanto, trabalhos com novilhas de raça Shorthorn $7,9,32$ em câmara climática a $32,2^{\circ} \mathrm{C}$ e com luz artificial substituindo a luz natural, destacaram que a temperatura ambiente elevada parecia exercer efeito mais decisivo que o número de horas de luz diário na mudança dos pelos dos bovinos.

Estudos do ciclo anual de queda e de substituição dos pelos de bovinos 1 revelaram que a muda dos pelos obedece ao fo- 
BARNABE, R. C. - Variaçōes estacionais no pelame de vacas da raça Jersey e sua correlação com a produção leiteira. Rev. Fac. Med. vet. Zootec. Univ. S. Paulo, 12:95-106, 1975.

toperiodismo, mas que, aparentemente, a temperatura ambiente também influi nesses processos.

Pesquisas com bovinos 11,12 , antes e depois de submetidos à tosa dos pelos e recobertos ou nāo com uma capa de plástico, sugeriram que a diferença apresentada por um mesmo animal em sua capacidade de tolerância ao calor, nas diversas estações do ano, pode ser atribuída às trocas sucessivas do pelame. Os animais de pelos longos eram pouco tolerantes ao calor, porém, uma vez tosados apresentavam sensível aumento de resistência.

Outras investigaçōes 35 sobre os efeitos da tosa não revelaram resultados tão acentuados. Houve, porém, uma significativa redução no ritmo respiratório dos tosados, quer nas condições ambientes, quer sob os efeitos de uma temperatura de $40^{\circ} \mathrm{C}$ em câmara climática.

Notou-se ainda que animais de pelos lisos e assentados apresentavam maior índice de perspiração e, como conseqüên. cia, melhor adaptação que os de pelos longos e ondulados, nos quais essa atividade sc revelou menos intensa 30 .

As características dos pelos e, provavelmente, seu ritmo de crescimento e queda, podem ser influenciadas pelo estado de nutriçāo do animal. Nesse particular, as condiçōes dos animais de origem européia poderiam ser sensivelmente agravadas nos trópicos onde ocorrem com muita freqüência carências de origem alimentar. Pela análise de pelos colhidos na linha da marrafa19, foi concluído que os teores em cálcio, fósforo, nitrogênio e potássio podem se constituir em expressão do estado de higidez dos animais. Demonstrou-se, ainda, que um estado de subnutrição imposto aos animais determina o aparecimento de pelos mais longos e ásperos, dificultando inclusive, sua troca por pelos mais lisos e assentados na época do verão, quando tal mudança se faz necessária para os animais enfrentarem os rigores desta estação16.

Relaçōes entre substâncias nitrogenadas e cinzas dos pelos foram estabelecidas $31 \mathrm{em}$ 40 vacas de raças leiteiras e mistas, em suas primeiras e terceiras lactaçōes. Os níveis de substâncias nitrogenadas eram iguais nos dois tipos, mas o teor de cinzas era maior nos animais de melhor aptidão leiteira, diminuindo, gradativamente, nos representantes das raças mistas. Concluiu- -se que a determinação das cinzas dos pelos poderia ser utilizada para identificar animais de alta e baixa capacidde de produção de liete.

Em estudo sobre o nível de produçāo leiteira e da alimentação em vacas submetidas a diferentes temperaturas ambientes 2 , verificou-se que os animais adaptam-se gradualmente às condiçōes do verāo, e que essa adaptação depende do isolamento periférico representado pela cobertura de pelos, tornando-se mais facilitada quando apresentam pelame típico de verão.

As possíveis relaçōes entre tipo de pelame e parasitas externos também têm sido investigadas, não se conseguindo, porém, estabelecer paralelos entre essas duas características. Notou-se, todavia, significativas diferenças entre indivíduos, com relação à resistência aos carrapatos 37 .

A raça Jersey tem demonstrado melhor tolerância ao calor se comparada a outras raças européias radicadas nos Estados Unidos27. Do mesmo modo foi assinalada a sua ambientaçāo em Porto Rico, na América Central15. No Estado de São Paulo, - estudo de um rebanho de gado Jersey ofereceu importantes dados sobre a adaptação desses animais, em termos de eficiência reprodutiva ${ }^{36}$.

\section{MATERIAL E MÉTODOS}

Para o estudo das características do pelame foram utilizadas 45 vacas da raça Jersey, oficialmente registradas e exploradas para produção leiteira em Jacareí, Estado de Sāo Paulo. Estes animais eram submetidos a regime de semi estabulação, com alimentação suplementar de concentrados, além de cana picada e silagem de milho, na época da seca.

O rebanho conta com permanente assistência veterinária e controle periódico de moléstias infecciosas e parasitárias.

As medidas do pelame foram tomadtas no mês de julho (inverno) e de janeiro (verão), utilizando-se uma régua de aço, provida de cursor, consoante técnica preconizada 20,34

As medidas do pelame que representam a distância vertical, em milimetros, existente entre a pele e o plano formado pela camada de pelos, foram tomadas em quatro regiōes do corpo: paleta, dorso, garupa e costado (fig. 1). 
BARNABE, R. C. - Variaçōes estacionais no pelame de vacas da raça Jersey e sua correlaçāo com a produção leiteira. Rev. Fac. Med. vet. Zootec. Univ. S. Paulo, 12:95-106, 1975.

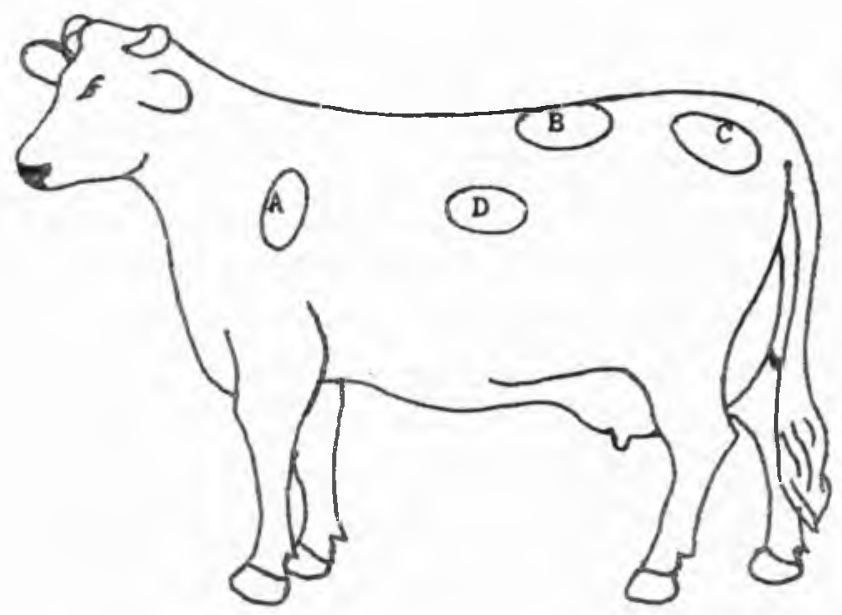

Fig. 1 - Regiōes do corpo do animal onde foram medidas as espessuras do pelame. A Paleta; B 5 Dorso; C - Garupa; D - Costado.

Os dados referentes às lactaçōes, cujo controle é feito oficialmente pela Associação Brasileira dos Criadores de Bovinos, foram obtidos de livros especiais da propriedade. Essas lactações correspondem à mesma época de medidas do pelame, isto é, referem-se a vacas que já estavam produzindo no inverno e que somente vieram completar o período após o mês de janeiro.

As producões obtidas no controle leiteiro sofreram ajustamentos para idade (6-8 anos), para período de lactaçăo (305 dias e para número de ordenhas diárias ( 2 ordenhas). Essa correção dos dados foi feita usando-se os coeficientes de tabela norteamericana, adaptados para gado Ayrshire, Guernsey e Jersey28.

Os resultados assim obtidos foram correlacionados 25 com as diferentes medidas da espessura do pelame, nas duas estaçōes inverno e verão.

\section{RESULTADOS E DISCUSSÃO}

I - Variação entre as duas estações (inverno e verão)

A fim de julgar as diferenças na espessura do pelame entre as estações de inverno e verão, foram tomadas medidas em quatro regiōes do corpo de 45 vacas da aça Jersey (Tabela 1). Cada valor representa a média de cinco medidas, tomadas em cada regiăo estudada.

A média geral do estudo foi de $3,08 \pm$ $0,22 \mathrm{~mm}$ e o coeficiente de variação igual a $20,45 \%$.

As médias obtidas para as regiōes, nas duas estaçōes, foram as constantes na Tabela 2 .

A análise de variância dos dados contidos na Tabela 1, proporcionou os seguintes resultados, resumidos na Tabela 3 .

Os dados analisados, submetidos ao teste de "F", revelaram apenas näo ser significativa a interação animais e regiāo do corpo (A x R).

A análise revelou ainda que as espessuras sāo distintas em relação às regiōes do corpo em que foram tomadas as medidas e que as estaçóes do ano alteram a espessura do pelame, sendo muito mais espesso no inverno que no verão, conforme indicam as interaçōes animais e estaços $(A \times E)$ e regiōes e estações $(R \times E)$.

Tal variação estacional já havia sido observada em gado bovino, por inúmeros pesquisadores $1,4,7,8,10,11,12,13,17,22,29,33,34,38,39$. 
BARNABE, R. C. - Variaçōes estacionais no pelame de vacas da raça Jersey e sua correlaçāo com a produção leiteira. Rev. Fac. Med. vet. Zootec. Univ. S. Paulo, 12:95-106, 1975.

T A B E L A 1

Espessura $(\mathrm{mm})$ do pelame de 45 vacas da raça Jersey, no inverno e no verāo e segundo as regiōes do corpo

\begin{tabular}{|c|c|c|c|c|c|c|c|c|}
\hline \multirow{2}{*}{$\begin{array}{c}\text { VACA } \\
\text { N. }\end{array}$} & \multicolumn{4}{|c|}{ I N V E R N O } & \multicolumn{4}{|c|}{ VER $\mathrm{A} O$} \\
\hline & Paleta & Dorso & Garupa & Costado & Paleta & Dorso & Garupa & Costado \\
\hline 1 & 3,53 & 2,82 & 2,12 & 3,18 & 0,71 & 1,41 & 1,06 & 1,41 \\
\hline 2 & 2,82 & 3,53 & 2,82 & 2,82 & 1,76 & 2,47 & 1,41 & 2,12 \\
\hline 3 & 3,18 & 3,53 & 2,12 & 4,24 & 2,12 & 1,76 & 1,41 & 1,41 \\
\hline 4 & 2,82 & 3,53 & 2,82 & 3,88 & 1,76 & 2,12 & 1,41 & 2,12 \\
\hline 5 & 2,82 & 3,88 & 1,76 & 3,88 & 1,76 & 2,12 & 1,41 & 2,12 \\
\hline 6 & 3,18 & 3,53 & 1,76 & 3,88 & 1,76 & 1,76 & 1,41 & 1,76 \\
\hline 7 & 4,59 & 4,24 & 2,82 & 4,24 & 2,12 & 2,82 & 1,41 & 2,47 \\
\hline 8 & 4,59 & 4,59 & 2,82 & 4,59 & 2,82 & 2,82 & 1,41 & 3,18 \\
\hline 9 & 3,18 & 4,24 & 2,12 & 2,82 & 2,12 & 2,82 & 1,41 & 2,12 \\
\hline 10 & 4,24 & 4,24 & 2,12 & 3,53 & 2,12 & 2,47 & 1,41 & 2,82 \\
\hline 11 & 2,47 & 4,59 & 2,47 & 2,82 & 1,06 & 2,12 & 1,06 & 2,12 \\
\hline 12 & 2,82 & 3,53 & 2,12 & 4,59 & 1,76 & 1,76 & 1,41 & 1,41 \\
\hline 13 & 4,24 & 3,53 & 2,12 & 3,53 & 3,53 & 3,53 & 2,12 & 3,53 \\
\hline 14 & 4,59 & 6,35 & 4,24 & 4,59 & 2,82 & 2,82 & 2,12 & 3,18 \\
\hline 15 & 4,59 & 4,24 & 3,18 & 4,94 & 2,12 & 3,18 & 1,41 & 2,82 \\
\hline 16 & 5,29 & 5,65 & 2,82 & 5,29 & 2,12 & 2,12 & 1,41 & 2,12 \\
\hline 17 & 3,88 & 3,53 & 2,12 & 3,53 & 1,41 & 1,41 & 1,06 & 1,41 \\
\hline 18 & 4,94 & 6,35 & 4,59 & 7,06 & 2,47 & 2,82 & 1,76 & 2,82 \\
\hline 19 & 2,82 & 3,53 & 2,12 & 2,82 & 2,12 & 2,12 & 1,41 & 1,76 \\
\hline 20 & 3,53 & 4,24 & 2,47 & 4,24 & 1,76 & 2,82 & 1,41 & 2,12 \\
\hline 21 & 5,65 & 4,94 & 2,82 & 4,59 & 2,47 & 2,82 & 1,41 & 2,82 \\
\hline 22 & 2,47 & 4,24 & 2,47 & 4,59 & 2,12 & 2,47 & 1,41 & 2,12 \\
\hline 23 & 2,12 & 3,53 & 3,53 & 4,59 & 2,12 & 2,47 & 1,76 & 2,82 \\
\hline 24 & 3,53 & 5,29 & 3,53 & 4,94 & 2,82 & 2,12 & 1,41 & 2,12 \\
\hline 25 & 4,24 & 6,35 & 2,82 & 6,35 & 2,12 & 2,82 & 1,06 & 2,47 \\
\hline 26 & 2,82 & 3,18 & 2,82 & 4,24 & 1,06 & 2,12 & 1,41 & 1,76 \\
\hline 27 & 2,47 & 2,82 & 1,76 & 2,82 & 1,76 & 2,12 & 1,41 & 2,12 \\
\hline 28 & 3,88 & 4,59 & 2,82 & 3,88 & 2,12 & 2,47 & 1,76 & 2,47 \\
\hline 29 & 5,29 & 5,65 & 5,65 & 7,06 & 1,41 & 2,82 & 1,76 & 2,47 \\
\hline 30 & 4,94 & 4,24 & 2,12 & 4,24 & 2,12 & 2,82 & 1,41 & 3,53 \\
\hline 31 & 7,77 & 4,24 & 4,24 & 3,88 & 2,47 & 3,18 & 2,82 & 3,18 \\
\hline 32 & 2,12 & 2,82 & 2,47 & 2,82 & 2,12 & 1,41 & 1,06 & 1,76 \\
\hline 33 & 5,65 & 5,65 & 3,53 & 7,06 & 4,24 & 3,88 & 3,53 & 4,94 \\
\hline 34 & 3,88 & 4,24 & 2,82 & 3,88 & 3,18 & 3,18 & 2,12 & 2,82 \\
\hline 35 & 3,53 & 4,24 & 2,47 & 3,88 & 2,47 & 2,47 & 1,41 & 2,82 \\
\hline 36 & 2,82 & 5,65 & 2,82 & 4,59 & 2,82 & 2,12 & 1,76 & 2,12 \\
\hline 37 & 2,47 & 3,18 & 1,76 & 2,82 & 2,12 & 2,47 & 1,41 & 2,47 \\
\hline 38 & 3,88 & 4,24 & 2,12 & 4,24 & 2,12 & 2,12 & 1,06 & 1,41 \\
\hline 39 & 9,18 & 6,00 & 3,88 & 5,29 & 2,82 & 2,82 & 1,41 & 3,18 \\
\hline 40 & 4,59 & 4,94 & 3,53 & 5,29 & 2,47 & 2,12 & 1,41 & 2,82 \\
\hline 41 & 3,88 & 7,06 & 4,24 & 7,77 & 3,18 & 2,82 & 1,41 & 3,18 \\
\hline 42 & 3,88 & 3,53 & 2,82 & 2,82 & 2,47 & 2,12 & 1,76 & 2,82 \\
\hline 43 & 10,94 & 6,71 & 5,65 & 6,00 & 5,65 & 4,24 & 2,12 & 6,35 \\
\hline 44 & 4,24 & 4,94 & 2,82 & 6,00 & 2,12 & 2,12 & 1,76 & 3,18 \\
\hline 45 & 2,12 & 2,82 & 2,47 & 3,53 & 2,47 & 2,47 & $\mathbf{1 , 4 1}$ & 3,18 \\
\hline
\end{tabular}


BARNABE, R. C. - Variações estacionais no pelame de vacas da raça Jersey e sua correlação com a produção leiteira. Rev. Fac. Med. vet. Zootec. Univ. S. Paulo, 12:95-106, 1975.

\section{T A B E L A 2}

Médias da espessura (mm) do pelame, nas diferentes regiōes do corpo, no inverno e no verão

\begin{tabular}{l|c|c|c|c}
\hline \multirow{2}{*}{$\begin{array}{c}\text { Estaçāo } \\
\text { do } \\
\text { ano }\end{array}$} & \multicolumn{4}{|c}{ REGIXo DO CORPO } \\
\cline { 2 - 5 } & Paleta & Dorso & Garupa & Costado \\
\hline \hline Inverno & 4,05 & 4,43 & 2,87 & 4,39 \\
Verão & 2,29 & 2,48 & 1,55 & 2,57 \\
\hline
\end{tabular}

Nota-se ainda, pelo exame da Tabela 3 , que há significativas diferenças na espessura do pelame entre indivíduos dentro das estações, o que significa dizer que há animais eletivamente dotados de menor espessura de pelame nas duas épocas do ano, que outros. Este fato se reveste de importância, pois admitida a hipótese, quase que universalmente aceita, de que animais de pelame menos espesso têm maior facilidade para se adaptar aos climas quentes, seria interessante que os trabalhos de seleção, dentro desse intervalo de variação, preservassem para a reprodução indivíduos que ostentassem essa particular característica.

As espessuras do pelame, tomadas nas diferentes regiōes do corpo, mantém entre si determinadas relaçōes, independentes das estações do inverno e do verão, de maneira que para fins de avaliação de um animal, as medidas poderiam ser tomadas em qualquer das duas épocas.

Entretanto, foi demonstrado que no inverno, quando submetidos à temperatura de $40^{\circ} \mathrm{C}$ em câmara climática, os animais dotados de maior espessura do pelame não apresentaram reaçōes tão acentuadas como no verão, mesmo quando na temperatura ambiente, isto é, fora da câmara climática. Admitida a maior importância da espessura do pelame no verão, relacionada com a adaptação dos bovinos nas regiōes tropicais e subtropicais $2,4,5,10,11,12,29$, nada mais recomendável do que sugerir-se a tomada dessas medidas, para fins de seleção, na estação mais quente do ano.

O desdobramento dos graus de liberdade dos componentes significativos, sob o ponto de vista estatístico, da Tabela 3 , possibilitou a confecção da Tabela 4 .
0 exame da Tabela 4 revela que não há uma espessura uniforme em todas as regiōes do corpo de um mesmo animal, em ambas as estaçōes. As diferenças de espessura nas regiōes do costado e dorso, quando confrontadas com as da paleta e garupa, são significativas, sendo as primeiras, de modo geral, mais espessas. Entretanto, ao se considerarem apenas as espessuras das regiōes do costado e dorso, não se encontraram diferenças significativas entre as duas, ao passo que, seguindo - mesmo critério para paleta e garupa, a primeira revelou-se mais espessa que a segunda, tanto no inverno como no verāo.

Esses resultados eram de se esperar, pois, em contínuo crescimento e queda $1,7,8,13,17,22,24,29,34,38,39$, os pelos não mantêm o mesmo comprimento: Além disso, sob temperaturas ambientes diferentes ou de acordo com as estaçóes do ano, os pelos podem alterar sua orientação, assentando-se sobre o corpo ou eriçando-se. E conhecido que os animais movimentam seus pelos, como um dos mecanismos de regulaçāo térmica, eriçando-os sob a ação do frio e dos ventos, tal como acontece com as penas das aves.

II - Correlaçōes entre espessura do pelame das diferentes regiōes do corpo e a produção leiteira dos animais.

As lactaçōes ajustadas das vacas em estudo poderāo ser melhor observadas na Tabela 5 .

A média geral foi de $3.166,88 \pm 1.170,00 \mathrm{k}$ e o coeficiente de variação igual a $24,0 \%$.

Os valores de "r" obtidos e referentes ao confronto das medidas de espessura do pelame em quatro regiōes do corpo com a produção leiteira, são as constantes da Tabela 6 .

Os coeficientes de correlações constantes da Tabela 6, conforme pode ser verificado, são todos negativos, tanto no inverno como no verão, e parecem indicar a provável tendência dos animais dotados de menores espessuras no pelame, apresentarem produçōes leiteiras mais elevadas. Dos oito coeficientes, apenas dois, referentes à espessura do pelame na paleta (inverno) e na garupa (verão), não se revelaram significativas, sob o ponto de vista estatístico. Os outros seis, representando o dorso, a garupa e o costado no inverno e a paleta, o dorso e o costado no verão, apresentaram significância, sugerindo esses resultados que novos experimentos poderão 
BARNABE, R. C. - Variaçōes estacionais no pelame de vacas da raça Jersey e sua correlação com a produção leiteira. Rev. Fac. Med. vet. Zootec. Univ. S. Paulo, 12:95-106, 1975.

\section{T A B E L A 3}

Análise da espessura do pelame, nas diversas regiōes do corpo dos animais - Paleta, Dorso, Garupa e Costado - em duas estações do ano (Inverno e Verão)

\begin{tabular}{l|r|r|c}
\hline \multicolumn{1}{c|}{ CAUSAS DA VARIAÇÃo } & G.L. & S.Q. & Q.M. \\
\hline \hline & 44 & 217,8313 & $4,9507^{* *}$ \\
Animais (A) & 3 & 94,5053 & $31,5018^{* *}$ \\
Regiōes do corpo (R) & 1 & 262,7417 & $262,7417^{* *}$ \\
Estaçōes do ano (E) & 132 & 61,4469 & 0,4655 \\
Animais x Regiōes (A x R) & 44 & 58,0116 & $1,3184^{* *}$ \\
Animais x Estaçōes (A x E) & 3 & 4,8844 & $1,6281^{* *}$ \\
Regiōes x Estaçōes (R x E) & 132 & 52,8356 & 0,4003 \\
Resíduo & 359 & 752,2568 & \\
\hline TOTAL & & & \\
\hline
\end{tabular}

** = significativo a $1 \%$

T A B E L A 4

Desdobramento dos graus de liberdade dos componentes significativos na análise da Tabela 3

\begin{tabular}{|c|c|c|c|}
\hline CAUSAS DE VARIAÇAOO & G.L. & S.Q. & Q.M. \\
\hline \multicolumn{4}{|l|}{ ESTAÇÓES（E) } \\
\hline & 1 & 262,7417 & $262,7417 * *$ \\
\hline Animais dentro do Inverno & 44 & 206,7957 & $4,6999 * *$ \\
\hline Animais dentro do Verāo & 44 & 69,0473 & $1,5693 * *$ \\
\hline Costado e Dorso x Paleta e & & & \\
\hline Garupa (dentro do Inverno) & 1 & 39,5836 & $39,5836 *$ \\
\hline Costado e Dorso x Paleta e & & & \\
\hline Garupa (dentro do Verāo) & 1 & 16,4288 & $16,4288 * *$ \\
\hline Costado x Dorso (dentro do Inverno) & 1 & 0,0139 & 0,0139 \\
\hline Costado x Dorso (dentro do Verão) & 1 & 0,1681 & 0,1681 \\
\hline Paleta x Garupa (dentro do Inverno) & 1 & 31,1757 & $31,1757 * *$ \\
\hline Paleta x Garupa (dentro do Verão) & 1 & 12,0195 & $12,0195 * *$ \\
\hline $\begin{array}{l}\text { A x R (Animais x Regiōes) } \\
\text { Resíduo }\end{array}$ & $\begin{array}{l}132 \\
132\end{array}$ & $\begin{array}{l}61,4469 \\
52,8356\end{array}$ & $\begin{array}{l}0,4655 \\
0,4003\end{array}$ \\
\hline TOTAL & 359 & 752,2568 & \\
\hline
\end{tabular}

** = significativo a $1 \%$ 
BARNABE, R. C. - Variações estacionais no pelame de vacas da raça Jersey e sua correlaçāo com a produçäo leiteira. Rev. Fac. Med. vet. Zootec. Univ. S. Paulo, 12:95-106, 1975.

TAB ELA 5

Lactaçōes ajustadas das vacas submetidas ao estudo de correlação e referentes ao período das medidas de espessura do pelame

\begin{tabular}{|c|c|c|c|}
\hline Vaca n. $^{0}$ & Lactação & Vaca $n .^{0}$ & Lactação \\
\hline 1 & $5.129,32$ & 24 & 3. 195,26 \\
\hline 2 & $4.430,73$ & 25 & $3.165,15$ \\
\hline 3 & $4.245,36$ & 26 & $3.162,37$ \\
\hline 4 & $4.226,91$ & 27 & $3.113,95$ \\
\hline 5 & $4.197,00$ & 28 & $3.032,39$ \\
\hline 6 & $4.129,04$ & 29 & $2.945,81$ \\
\hline 7 & $4.083,20$ & 30 & $2.881,89$ \\
\hline 8 & $3.999,74$ & 31 & $2.834,48$ \\
\hline 9 & $3.913,86$ & 32 & $2.726,78$ \\
\hline 10 & $3.888,17$ & 33 & $2.584,52$ \\
\hline 11 & $3.718,66$ & 34 & $2.501,56$ \\
\hline 12 & $3.642,31$ & 35 & $2.497,34$ \\
\hline 13 & 3. 596,03 & 36 & $2.476,30$ \\
\hline 14 & $3.569,45$ & 37 & $2.437,80$ \\
\hline 15 & 3. 560,57 & 38 & $2.389,33$ \\
\hline 16 & $3.431,62$ & 39 & $2.259,58$ \\
\hline 17 & $3.370,69$ & 40 & 2. 158,96 \\
\hline 18 & $3.317,27$ & 41 & $2.104,60$ \\
\hline 19 & $3.036,78$ & 42 & $2.094,06$ \\
\hline 20 & $3.304,16$ & 43 & 1. 958,23 \\
\hline 21 & $3.236,63$ & 44 & $1.802,43$ \\
\hline 22 & $3.234,56$ & 45 & 1. 453,79 \\
\hline 23 & $3.201,00$ & & \\
\hline
\end{tabular}

TA B E L A 6

Correlações entre medidas tomadas em quatro regiōes do corpo dos animais, no inverno e no verão com suas lactações

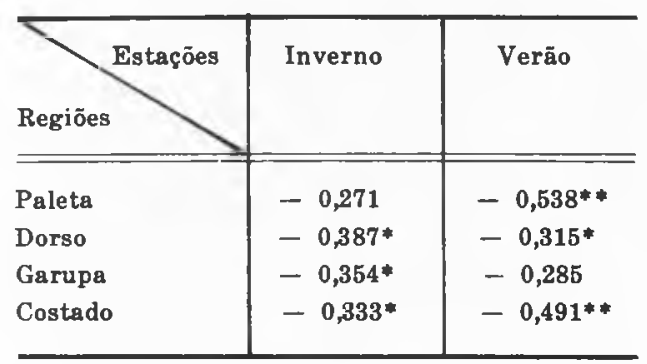

* = significativo a $5 \%$

** = significativo a $1 \%$ ser tentados, abrangendo inclusive maior número de regiōes corpóreas, bem como espacos de tempo menores entre as medidas, a fim de se surpreenderem relaçōes mais estreitas entre as características do pelame e a produção leiteira dos animpis.

As maiores espessuras do pelame 34 tiveram influência significativa nas reações dos animais, relacionadas com a temperatura retal e a determinados valores hemométricos, causando efeitos desfavoráveis de adaptação (aumento da temperatura e queda do número de glóbulos vermelhos e taxa de hemoglobina). Como se vê, os animais de pelame mais espesso sofreram os efeitos do calor no verão mais que os dotados de menor espessura e assim não será descabido supor que tais condiçoes tenham repercussões na produção leiteira. Aliás, é exatamente isso o que nos parecem revelar os coeficientes de correlação encontrados entre espessura do pelame e produçāo leiteira.

Não se deve inferir, destas investigaçōes, como é óbvio, que vacas dotadas de pelame menos espesso produzirão, obrigatoriamente, mais leite. Todavia, as 45 vacas estudadas revelaram tendência de as que produziram mais leite apresentarem pelame menos espesso.

Não deixa, também, de ser significativo o fato de os animais estudados terem estado, praticamente, sob as mesmas condições de manejo há longos anos e, principalmente o fato das relações entre espessura do pelame e produção leiteira coincidirem com relaçōes entre espessura do pelame e tolerância ao calor, estas últimas observadas em diferentes raças e em diversas regiōes tropicais e subtropicais 1,5,6,7,8,9,11,12,21 $22,29,30,33,34,38,39$

De qualquer modo, nāo seria demasiado sugerir, à luz dos resultados desta investigação que, na seleção de vacas da raça Jersey e, com muita probabilidade de outras raças, em condições tropicais e subtropicais, que a espessura do pelame seja levada na devida consideração, uma vez que esta característica mantém relaçōes com a tolerância ao calor e provavelmente com a produtividade dos animais.

\section{O N C L U S Õ E S}

Os resultados obtidos no presente trabalho, permitiram as seguintes conclusões: 
BARNABE, R. C. - Variações estacionais no pelame de vacas da raça Jersey e sua correlação com a produção leiteira. Rev. Fac. Med. vet. Zootec. Univ. S. Paulo, 12:95-106, 1975.

1 - Os animais comportaram-se igualmente quanto à espessura do pelame em relação às regiões do corpo, independentemente da estação do ano. Assim, tomar medidas em uma das estações do ano é suficiente para colheita de dados, no referente às relações que mantém entre si as regiões do corpo estudadas.

2 - Os animais apresentaram espessura de pelame diversa uns dos outros, indicando a possibilidade de serem selecionados animais com pelame mais condizente para climas de elevadas temperaturas ambientes.

3 - As espessuras de pelame apresentaram-se distintas em relação às regiōes do corpo em que foram medidas. Assim, as espessuras medidas no dorso e no costado, tanto no inverno como no verão, sempre foram superiores às tomadas na paleta e na garupa.
4 - As estações do ano alteraram a espessura do pelame, apresentando os animais, em todas as regiōes medidas, camadas de pelos mais espessas no inverno que no verão.

5 - Não houve diferença significativa entre as regiões do costado e dorso, nas duas estaçōes, o que leva a supor que apenas uma medida, em uma das duas regiões, torna-se suficiente para a colheita dos dados.

6 - A espessura do pelame da paleta é mais espessa que a da garupa, tanto no inverno como no verão.

7 - Os animais de pelame menos espesso tendem apresentar índices de lactações mais elevados.

8 - A correlação entre espessuras do pelame com a produção leiteira é mais evidente nas regiões do dorso, garupa e costado no inverno, bem como na paleta, dorso e costado no verão.

BARNABE, R. C. - Seasonal variations in coat thickness of Jersey breed cows and their correlations with milk production. Rev. Fac. Med. vet. Zootec. Univ. S. Paulo, 12:95-106, 1975.

SUMMARY: Coat thickness of 45 Jersey cows was measured in two seasons of year (winter and summer) in order to calculate the correlations between hair coat thickness and milk production. All measurements were taken in four selected regions of animal body: shoulders, loin, rump and ribs.

Differences in coat thickness were observed amongst animals and amongst regions of animal body either in summer or winter seasons.

Correlations between coat thickness and milk production seem to indicate that higher milk production cows have thinnest hair coat, being the most significant those coefficients related to the regions of shoulders and ribs in summer time.

UNITERMS: Seasonal variations*; Coat thickness*; Milk production*. 
BARNABE, R. C. - Variações estacionais no pelame de vacas da raça Jersey e sua correlaçāo com a produçāo leiteira. Rev. Fac. Med. vet. Zootec. Univ. S. Paulo, 12:95-106, 1975.

\section{REFERENCIAS BIBLIOGRAFICAS}

1. BERMAN, A. \& VOLCANI, R. - Seasonal and regional variations in coat characteristics of dairy cattle. Aust. J. agric. Res., $12(3): 528-38,1961$

2. BERMAN, A.; AMIR, S.; VOLCANI, R. - The relationship between the rate of heat production and the level of milk production in a subtropical climate. Aust. J. agric. Res., 14:874-81, 1963.

3 BOND, J.; McDOWELL, R. E.; CURRY, W. A.; WARWICK, E. J. - Reproductive performance of milking Shorthorn heifers as affected by constant high environmental temperature. J. Anim. Sci., 19(4):1317, 1960.

4. BOND, J.; WELDY, J. R.; McDOWELL, R. E.; WARWICK, E. J. - Responses of summer conditioned heifers to $900^{\circ}$ F. J. Anim. Sci., $20(4): 966,1961$.

5. BONSMA, J. C. - Breeding cattle for increased adaptability to tropical and subtropical environments. J. agric. Sci., 39 (2) :204-21, 1949.

6. Heat tolerant cattle bred at Mara - Degeneration of exotics in hot climate overcome by correct breeding policy. Pasture research and veterinary science cooperate with animal husbandry. apud Anim. Breed. Abstr. $20: 314,1952$.

7. BONSMA, J. C. \& PRETORIUS, A. J. Influence of colour coat cover on adaptability of cattle. $F m g$. S. Afr., $18(2): 101-17,1943$.

8. BONSMA, J. C.; VAN MARLE, J.; HOFMEYR, J. H. - Climatological research on animal husbandry and its significance in the development of beef-cattle production in colonial territories. Emp. J. exp. Agric., 21(83): $154-75,1953$.

9. BRODY, S. - Bioenergetics and growth, with special reference to the efficiency complex in domestic animals. New York, Reinhold Publ., 1945.

10. DOWLING, D. F. - An experimental study of heat tolerance of cattle. Aust. J. agric. Res., 7 (5).469-81, 1956.

11. DOWLING, D. F. - The significance of the coat in heat tolerance of cattle. Aust. J. agric. Res., 10(5):744-48, 1959.
12. DOWLING, D. F. - The significance of the coat in heat tolerance of cattle. II. Effect of solar radiation on body temperatures. apud Anim. Breed. Abstr., 29 (1):42, 1960.

13. DOWLING, D, F, \& NAY, T. - Cyclic changes in the follicles and hair coat in cattle. Aust. J. agric. Res., 11(6): 1064-71, 1960.

14. FINDLAY, J. D. \& BEAKLEY, W. B. La fisiologia del medio ambiente de los mamiferos domesticos. In: HAMMOND, J. Avances in fisiologia zootecnia. Zaragoza, Acribia, 1959, p. 304-58.

15. GAZTAMBIDE ARRILLAGA, C.; HEN. NING, W. L.; MILLER, R. C. - The effects of environmental temperature and relative humidity on the acclimation of cattle to the tropics. J. Anim. Sci., 11 (1):50-60, 1952.

16. HAYMAN, R. H. - Hair growth in cattle: proceedings of a symposium held at Canberra, Australia, 1964.

17. HAYMAN, R. H. \& NAY, T. - Observations on hair growth and shedding in cattle. Aust. J. agric. Res., 12(3): 513-27, 1961.

18. KASSAB, S. A. On maternal and some others influences on birth weight, growth and hair coat in two Dutch cattle breeds. apud Anim. Breed Abstr., 32 (4) :2828, 1964.

19. KEATING, J. - Hair analysis in cattle as an index of mineral status. Irish vet. J., 14 (4) : 74-8, 1960.

20. LEE, D. H. K. - Manual of field studies on the heat tolerance of domestic animals. Rome, FAO, 1953. (Development Paper Agriculture, 38).

21. LE ROUX, J. D. - The value of camps on a cattle ranch. apud Anim. Breed Abstr., $20: 216,1952$.

22. McDOWELL, R. E.; BOND, J.; MeDANIEL, B. T.; WARWICK, E. J. Influence of $90 .^{\circ} \mathrm{F}$ environmental temperature on certain physiological responses of milking Shorthorn heifers. J. Anim. Sci., 19 (4): 1329, 1960.

23. PAN, Y. S. - Variation in hair characters over the body in Sahiwal zebu and Jersey cattle. Aust. J. agric. Res., 15 (2) :346-56, 1964. 
BARNABE, R. C. - Variações estacionais no pelame de vacas da raça Jersey e sua correlação com a produção leiteira. Rev. Fac. Med. vet. Zootec. Univ. S. Paulo, 12:95-106, 1975.

24. PHILliPS, R. W. - La cria de ganado en ambientes desfavorables. Rome, FAO, 1949. (Estudios Agropecuarios, 1 ).

25. Pimentel Gomes, F. - Curso de estatística experimental. 2. ${ }^{a}$ ed. Piracicaba, Ediçōes Didáticas, 1963.

26. RHOAD, A. O. - El clima y la producción pecuária. Res., $292(14): 18744-45$, 1946.

27. RHOAD, A. O. - Some observations in the response of purebred Bos taurus and Bos indicus cattle and their crossbred types to certain conditions of environment. Rec. Proc. Amer. Soc. An. Prod. 284-95, 1938.

28. RICE, V. A.; ANDREWS, F. N.; WARWICK, E. J.; LEGATES, J. E. Breeding and improvement of farm animals. 5th ed. New York, McGrawHill Book Co., 1957, p. 404-05, 408-10.

29. SCHLEGER, A. V. \& TURNER, H. G. Analysis of coat characters of cattle. Aust. J. agric. Res., 11(5):875-85, 1960 .

30. SCHLEGER, A. V. \& TURNER, H. G. Sweating rates of cattle in the field and their reaction to diurnal and seasonal changes. Aust. J. agric. Res., 16 (1) :92-106, 1965.

31. TOSCANO, G. \& GAIDANO, R. - Nitrogenous substances and ash in hair of cows of different breeds. Critical considerations on ethnic differentiation and productive capacity. apud Anim. Breed. Abstr., 29(1):127-38, 1960.

32. TURNER, H. G. \& SCHLEGER, A. V. Field observations on associations between coat type and performance in cattle. Proc. A. S. A. P., 2:112-14, 1958.
33. TURNER, H. G. \& SCHLEGER, A. V. The significance of coat type in cattle. Aust. J. agric. Res., $11(4): 645-63,1960$.

34. VEIGA, J. S.; BARNABE, R. C.; GHION, E.; AGGIO, C. A. C. - Aspectos fisiológicos associados com a adaptaçāo de bovinos nos climas tropicais e subtropicais. II. Espessura do pelame de revestimento do corpo, peso dos pelos e suas relaçōes com a tolerância ao calor. Arq. Esc. Vet., Minas Gerais, 16:113-37, 1964.

35. VEIGA, J. S.; BARNABE, R. C.; GHION E.; AGGIO, C. A. C.; SACILLOTO J. M. - Aspectos fisiológicos associados com a adaptação de bovinos nos climas tropicais e subtropicais. II. Efeitos da tosquia no verão. Arq. Esc. Vet. Minas Gerais, 17:145-61, 1965.

36. VEIGA, J. S. \& BARNABE, R. C. Eficiência reprodutiva de um rebanho de gado Jersey criado no Vale do $\mathrm{Pa}$ raíba (Estado de São Paulo). Rev. Fac. Med. vet., S. Paulo, 7(2):389-400, 1965.

37. WILKINSON, P. R. - Selection of cattle for tick resistance, and the effect on herds of different susceptibility on Boophilus populations. apud Anim. Breed. Abstr., 31(2):193, 1963.

38. YEATES, N. T. M. - Photoperiodicity in cattle. I. Seasonal changes in coat character and .their importance in heat regulation. Aust. J. agric. Res., 6 (6) : 891-902, 1935.

39. YEATES, N. T. M. - Photoperiodicity in cattle. II. The Equatorial light environment and its effect on the coat of European cattle. Aust. J. agric. Res., 8(6) : 733-39, 1957.

Recebido para publicação em 19-8-75

Aprovado para publicação em 17-9-75 